\title{
Simulink and Simelectronics based Position Control of a Coupled Mass-Spring Damper Mechanical System
}

\author{
Okubanjo A. A., Oyetola O. K., Olaluwoye O. O. \\ Department of Computer and Electrical and Electronics Engineering, Olabisi Onabanjo University, Ogun, Nigeria
}

\begin{tabular}{l} 
Article Info \\
\hline Article history: \\
Received May 22, 2018 \\
Revised Aug 20, 2018 \\
Accepted Aug 26, 2018 \\
\hline
\end{tabular}

Keyword:

Lagrange equation

Mass spring damper

Mathematical model

Position control

Simulink and Simelectronics

\begin{abstract}
This paper presents the use of Simelectronics Program for modeling and control of a two degrees-of freedom coupled mass-spring-damper mechanical system. The aims of this paper are to establish a mathematical model that represents the dynamic behaviour of a coupled mass-spring damper system and effectively control the mass position using both Simulink and Simelectronics. The mathematical model is derived based on the augmented Lagrange equation and to simulate the dynamic accurately a PD controller is implemented to compensate for the oscillation sustained by the system as a result of the complex conjugate pair poles near to the imaginary axis. The input force has been subjected to an obstacle to mimic actual challenges and to validate the mathematical model a Simulink and Simelectronics models were developed, consequently, the results of the models were compared. According to the result analysis, the controller tracked the position errors and stabilized the positions to zero within a settling time of $6.5 \mathrm{sec}$ and significantly reduced the overshoot by $99.5 \%$ and $99.7 \%$ in Simulink and Simelectronics respectively. Furthermore, it is found that Simelectronics model proved to be capable having advantages of simplicity, less timeintense and requires no mathematical model over the Simulink approach.
\end{abstract}

Copyright (c) 2018 Institute of Advanced Engineering and Science. All rights reserved.

Corresponding Author:

A.A.Okubanjo,

Department of Computer and Electrical and Electronics Engineering,

Olabisi Onabanjo University,

College of engineering and Envinromental Studies,

Ibogun Campus, Ogun State, Nigeria.

Email: okubanjo.ayodeji@oouagoiwoye.edu.ng

\begin{tabular}{|c|c|c|c|}
\hline \multicolumn{2}{|c|}{ Nomenclatures } & \multicolumn{2}{|c|}{ Abbreviations } \\
\hline$m_{1,} m_{2}$ & $\begin{array}{l}\text { Translating inertial elements } \\
\text { (masses) }\end{array}$ & DOF & Degree of freedom \\
\hline$k_{1}, k_{2}$ & Spring stiffness coefficients & $\mathrm{EOM}$ & Equations of Motion \\
\hline $\mathrm{b}_{1}, \mathrm{~b}_{2}$ & Viscous damping coefficients & MSD & Mass Spring Damper \\
\hline$L$ & Lagrange's function & & \\
\hline $\mathrm{T}$ & Kinetic energy & & \\
\hline$U$ & Potential energy & & \\
\hline$D$ & Rayleigh's dissipative function & & \\
\hline $\mathrm{x}_{1}, \mathrm{x}_{2}$ & $\begin{array}{l}\text { Generalized coordinates } \\
\text { displacement }\end{array}$ & & \\
\hline$Q_{i}$ & Generalized forces & & \\
\hline$\dot{x_{1}}, \dot{x_{2}}$ & $\begin{array}{l}\text { Velocities of the masses } m_{1} \text { and } \\
m_{2}\end{array}$ & & \\
\hline$\ddot{x}_{1}, \ddot{x}_{2}$ & $\begin{array}{l}\text { Accelerations of the masses } m_{1} \\
\text { and } m_{2}\end{array}$ & & \\
\hline
\end{tabular}




\section{INTRODUCTION}

In a mechanical systems, accurate control of motion (such as position, velocity) is a fundamental concern to control engineers. Thus, the position control tries to adjust the dynamic of the mass while achieving the constraints imposed by the force positioning the mass. Consequently, the control problems involve finding suitable mathematical models that describe the dynamic behaviour of the physical mass spring dampers (MSD) model to permit suitable controller design and allow corresponding control strategies to realize the expected system response and performance. Mass-spring-damper systems (MSD) are widely used in robot manipulator control [1], [2],vehicle suspension systems for shock absorption in automobiles [3]-[7], Mechatronic application especially in piezoelectric for vibration energy harvester [8]-[10] and motion control application [11]-[12]. Recently, MSD systems are in increasing demand for hybrid vehicle suspension to increase passenger ride comfort and vehicle stability over cracks and uneven pavement.

Tarik et al [1] developed a mass spring damper model with MATLAB graphical user interface which permits flexibility in the choice of control strategies on the model through model parameters adjustment. Sivák and Hroncová [13] presented equations of motion (EOM) of a mechanical system with two degrees of freedom in MATLAB/Simulink using state space and transfer function. The conclusion of their work is that Newton's law and Lagrange's equation resulted in the same solution. Furthermore, in [14], the author presented Simmechanics and Simulink models for car automobile suspension and implemented proportional-integral-derivative (PID) control strategy to minimize body acceleration. In [15], [16] , the authors established mass spring damper models based on Newton's law of motion to derive a state-space model for numerical computation with the aids of MATLAB and Simulink. An author in [17] examined the effect of the position of the damper in systems with multi-degree of freedom. Their research works concluded that displacement of an oscillator that affected by the force show more energy absorption for low displacement. In [18]-[20], the authors presented mathematical modeling of a mass spring damper system in MATLAB and Simulink. The author in [21], presented control of coupled mass spring damper system using polynomial structures approach. Malas and co-worker [22] presented a novel control strategy for inducing sif-sustained oscillation of a single degree-of-freedom MDS mechanical systems. The researchers concluded in their work that the proposed control model is capable of generating stable self-excited oscillation at the natural frequency regardless of the value of the control gain.

The objectives of this paper are to establish a mathematical model that represent the dynamic behaviour of a coupled mass spring damper systems and effectively control the mass position using both Simulink and Simelectronics as simulation tools

\section{RESEARCH METHOD}

We derived the equations of motion (EOM) of a coupled mass spring damper systems using secondorder, ordinary differential equations and to simulate dynamic accurately [23] the Lagrange's equation was adopted. The motivation for chosen Lagrange's equation over Newton's law or D'Alembert principle is that it allows significant simplification of the geometry of the system motion for solving large complex systems and also eliminates explicit rewriting all forces acting on the body. The mathematical model is formulated based on energy property of Lagrange approach and the control strategy and Simulink simulation are expanded on the derived mathematical model. However, the langrage's equation does not improvise for dissipative (damping) force in the mechanical system, hence, Rayleigh's dissipation function is introduced into Lagrange's equation to account for dissipative force in the model and we refer to this as augmented Lagrange's equation. In order to describe the physical motion of a coupled mass spring damper systems, we need to choose a set of variables or coordinates which are often referred to as generalized coordinates. Thus, the displacement of the masses is chosen as the generalized coordinates.

\subsection{Mathematical modeling}

The dynamic of the mass spring damper systems with two degrees of freedom (DOF) movement is explicitly derived based on Lagrange's equation to expound the problems involved in dynamic modeling. Figure 1 depicts a coupled mass spring damper systems, where two masses $m_{1}$ and $m_{2}$ are linked to a parallel spring-damper configuration with spring stiffness coefficients $k_{1}$ and $k_{2}$ and viscous damping coefficients $b_{1}$ and $b_{2}$ for mass $m_{1}$ and $m_{2}$ respectively. The force, $F(t)$, acts on mass 1 and the energy is transmitted to mass 2 via the springs and some part of energy is absorbed by the dampers

The systems performs linear motion along the axes of the springs and dampers. For simplicity, we assume the following assumptions in the model:

a. The springs are linear

b. The dampers are linear and

c. The weight of the springs are assumed to be negligible. 


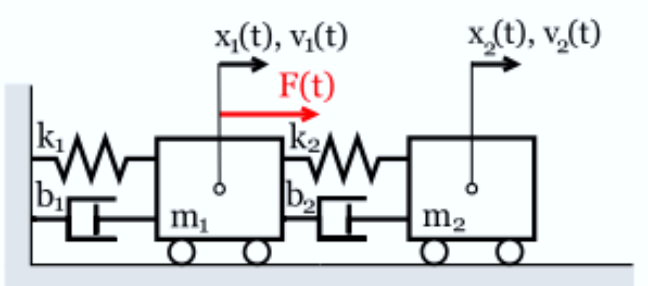

Figure 1. A coupled mass spring damper systems adapted from [8]

The equations of motion (EOM) for a mechanical system with 2-DOF can be derived by an augmented.

Lagrange's equation in the form

$$
\begin{aligned}
& \frac{d}{d t}\left(\frac{\partial L}{\partial \dot{q}_{i}}\right)-\left(\frac{\partial L}{\partial q_{i}}\right)+\left(\frac{\partial D}{\partial \dot{q}_{i}}\right)=Q_{i} \\
& q_{i}=\left(x_{1}, x_{2}\right)
\end{aligned}
$$

Where, ${ }^{q_{i}}$ is the generalized coordinates to describe the displacement of the masses.

First we calculate the kinetic energy, T, and the (augmented) potential energy, $U$, of the system, the kinetic energy of a coupled mass spring damper systems as function mass velocity is expressed as:

$$
T=\frac{1}{2} m_{1} \dot{x}_{1}^{2}+\frac{1}{2} m_{2} \dot{x}_{2}^{2}
$$

The augmented potential energy is expressed as:

$$
\begin{aligned}
& U=\frac{1}{2} k_{1} x_{1}^{2}+\frac{1}{2} k_{2}\left(x_{1}-x_{2}\right)^{2} \\
& U=\frac{1}{2} k_{1} x_{1}^{2}+\frac{1}{2} k_{2} x_{1}^{2}-k_{2} x_{1} x_{2}+\frac{1}{2} k_{2} x_{2}^{2}
\end{aligned}
$$

Rayleigh dissipative function account for damping force in the mechanical system and it is expressed as:

$$
\begin{aligned}
& D=\frac{1}{2} b_{1} \dot{x}_{1}^{2}+\frac{1}{2} b_{2}\left(\dot{x}_{1}-\dot{x}_{2}\right)^{2} \\
& D=\frac{1}{2} b_{1} \dot{x}_{1}^{2}+\frac{1}{2} b_{2} \dot{x}_{1}^{2}-b_{2} \dot{x}_{1} \dot{x}_{2}+\frac{1}{2} b_{2} x_{1}^{2}
\end{aligned}
$$

Generalized forces:

$$
Q_{1}=F, Q_{2}=0
$$

The Lagrange formulation defines the behaviour of a dynamic systems in terms of work and energy stored in the system [24]. 
The augmented Lagrange function $\mathrm{L}$ is denoted as:

$$
\begin{aligned}
& L=T-U \\
& L=\frac{1}{2}\left(m_{1} x_{1}^{2}+m_{2} x_{2}^{2}\right)-\left(\frac{1}{2} k_{1} x_{1}^{2}+\frac{1}{2} k_{2} x_{1}^{2}-k_{2} x_{1} x_{2}+\frac{1}{2} k_{2} x_{2}^{2}\right)
\end{aligned}
$$

We evaluate the following derivatives based on equation Equation (7) and Equation (10):

$$
\begin{aligned}
& \frac{d}{d t}\left(\frac{\partial L}{\partial x_{1}}\right)=m_{1} \ddot{x}_{1} \\
& \frac{d}{d t}\left(\frac{\partial L}{\partial \dot{x}_{2}}\right)=m_{2} \dot{x}_{2} \\
& \left(\frac{\partial L}{\partial x_{1}}\right)=-k_{1} x_{1}-k_{2} x_{1}+k_{2} x_{2} \\
& \left(\frac{\partial L}{\partial x_{2}}\right)=-k_{2} x_{2}+k_{2} x_{1} \\
& \left(\frac{\partial D}{\partial \dot{x}_{1}}\right)=b_{1} \dot{x}_{1}+b_{2} \dot{x}_{1}-b_{2} \dot{x}_{2} \\
& \left(\frac{\partial D}{\partial x_{2}}\right)=b_{2} \dot{x}_{1}+b_{2} \dot{x}_{2}
\end{aligned}
$$

For generalized coordinate ${ }^{x_{1}}$, the Lagrange's equation is:

$$
\frac{d}{d t}\left(\frac{\partial L}{\partial \dot{x}_{1}}\right)-\left(\frac{\partial L}{\partial x_{1}}\right)+\left(\frac{\partial D}{\partial \dot{x}_{1}}\right)=Q_{1}
$$

After substitution of the derived derivatives in Equation (11), Equation (13), and Equation (15) in Equation (17), we obtain equation of motion for mass 1 in this form:

$$
m_{1} \ddot{x_{1}}+\left(b_{1}+b_{2}\right) \dot{x_{1}}-b_{2} \dot{x}_{2}+\left(k_{1}+k_{2}\right) x_{1}-k_{2} x_{2}=F
$$

Similarly, for the generalized coordinate $x_{2}$, the Lagrange's equation is:

$$
\frac{d}{d t}\left(\frac{\partial L}{\partial \dot{x}_{2}}\right)-\left(\frac{\partial L}{\partial x_{2}}\right)+\left(\frac{\partial D}{\partial \dot{x}_{2}}\right)=Q_{2}
$$


In the same vein, substitution of the derived derivatives in Equation (12), Equation (14), and Equation (16) in Equation (19), we obtain equation of motion for mass 2 in this form

$$
m_{2} \ddot{x}_{2}-b_{2} \dot{x}_{1}+b_{2} \dot{x}_{2}-k_{2} x_{1}+k_{2} x_{2}=0
$$

The EOM in Equation (18) and Equation (20) are re-arrange to facilitate the implementation of the equations in Simulink as:

$$
\begin{aligned}
& \ddot{x}_{1}=\frac{-\left(b_{1}+b_{2}\right)}{m_{1}} \dot{x}_{1}+\frac{b_{2}}{m_{2}} \dot{x}_{2}-\frac{\left(k_{1}+k_{2}\right)}{m_{1}} x_{1}+\frac{k_{2}}{m_{1}} x_{2}+\frac{F}{m_{1}} \\
& \ddot{x_{2}}=\frac{b_{2}}{m_{2}} \dot{x}_{1}-\frac{b_{2}}{m_{2}} \dot{x}_{2}+\frac{k_{2}}{m_{2}} x_{1}-\frac{k_{2}}{m_{2}}
\end{aligned}
$$

The derived EOM is further written in terms of mass, damping, stiffness matrices and $F, x, x, x$ are force, displacement, velocity and acceleration vectors respectively and they are presented as:

$$
\left[\begin{array}{cc}
m_{1} & 0 \\
0 & m_{2}
\end{array}\right]\left[\begin{array}{c}
. . \\
x_{1} \\
. . \\
x_{2}
\end{array}\right]+\left[\begin{array}{cc}
b_{1}+b_{2} & -b_{2} \\
-b_{2} & b_{2}
\end{array}\right]+\left[\begin{array}{cc}
k_{1}+k_{2} & -k_{2} \\
-k_{2} & k_{2}
\end{array}\right]=\left[\begin{array}{c}
F \\
0
\end{array}\right]
$$

In the light of Equation (23), the EOM obtained by using Lagrange's equation for linear systems revealed that inertial, stiffness matrices as well as damping matrix if modeled by Rayleigh's function are symmetric

\subsection{State space representation of the model}

A state space representation is a time domain approach of modeling muiltiple input multiple output system. However, complex system with many degree-of-freedom, description of such systems with differential equations are often time intense and burdensome. So, state space representation of the systems serves as an alternative approach to alleviate the challenges. Also, the state space representation of a system replaces the higher-order differential equations with a single first-order matrix differential equation that gives an expedient and concise way to model and analyze systems with multiple inputs and outputs. The state model is notably advantageous when applied to simulation. Hence, the state and output equations are given in [25] as:

$$
\begin{aligned}
& \dot{x}(t)=A . . x(t)+B \cdot u(t) \\
& y(t)=C \cdot x(t)+D \cdot u(t)
\end{aligned}
$$

Where, $\mathrm{x}, \mathrm{y}, \mathrm{u}, \mathrm{A}, \mathrm{B}, \mathrm{C}, \mathrm{D}$ are the state vector, output vector, input vector, system matrix, input matrix, output matrix and feedback matrix respectively.

Let define,

$$
\begin{aligned}
& \frac{d^{2} x_{1}}{d t^{2}}=\frac{d v_{1}}{d t}, \frac{d^{2} x_{2}}{d t^{2}}=\frac{d v_{2}}{d t} \\
& \frac{d x_{1}}{d t}=v_{1}, \frac{d v_{2}}{d t}=v_{2}
\end{aligned}
$$

So that $x_{1}, x_{2}, v_{1}, v_{2}$ are selected as state variables and equation Equation (21) and Equation (22) 
are presented in state space equation in vector matrix form as:

$$
\left[\begin{array}{c}
\dot{x_{1}} \\
\dot{v_{1}} \\
\dot{x_{2}} \\
\dot{v_{2}}
\end{array}\right]=\left[\begin{array}{cccc}
0 & 0 & 1 & 0 \\
-\frac{\left(k_{1}+k_{2}\right)}{m_{2}} & \frac{k_{2}}{m_{1}} & \frac{-\left(b_{1}+b_{2}\right)}{m_{1}} & \frac{b_{2}}{m_{1}} \\
0 & 0 & 0 & 1 \\
\frac{k_{2}}{m_{2}} & \frac{-k_{2}}{m_{2}} & \frac{b_{1}}{m_{1}} & \frac{-b_{2}}{m_{2}}
\end{array}\right]\left[\begin{array}{c}
x_{1} \\
x_{2} \\
v_{1} \\
v_{2}
\end{array}\right]+\left[\begin{array}{c}
0 \\
\frac{1}{m_{2}} \\
0 \\
0
\end{array}\right] F(t)
$$

And the output are the displacement $\mathrm{x}_{1}$ and $\mathrm{x}_{2}$ of masses $\mathrm{m}_{1}$ and $\mathrm{m}_{2}$ respectively. Hence,

$$
y(t)=\left[\begin{array}{llll}
1 & 0 & 0 & 0 \\
0 & 1 & 0 & 0
\end{array}\right]\left[\begin{array}{l}
x_{1} \\
x_{2}
\end{array}\right]+\left[\begin{array}{l}
0 \\
0
\end{array}\right]
$$

\section{MODELING OF A COUPLED MASS SPRING DAMPER SYSTEMS USING SIMELECTRONICS AND SIMULINK}

A coupled mass spring damper system is modeled and simulated using SimElectronics toolbox in MATLAB software as shown in Figure 2. In MATLAB software, SimElectronics is a components libraries and special simulation features for modeling and stimulating physical system in the Simulink environment. The distinct feature of SimElectronics is the use of physical network approach to model electronic and mechatronic systems which mimic the physical system. Therefore, the use of physical connection permits a bidirectional flow of energy between components. The SimElectronics permit the use of Simulink library in modeling in which Simulink-PS-converter block converts the Simulink signal to physical system signal and PS-Simulink converter block does the reverse [26]. However, Simulink is a block diagram environment embedded in the MATLAB that allows modeling and simulation of multi-domain dynamics systems.

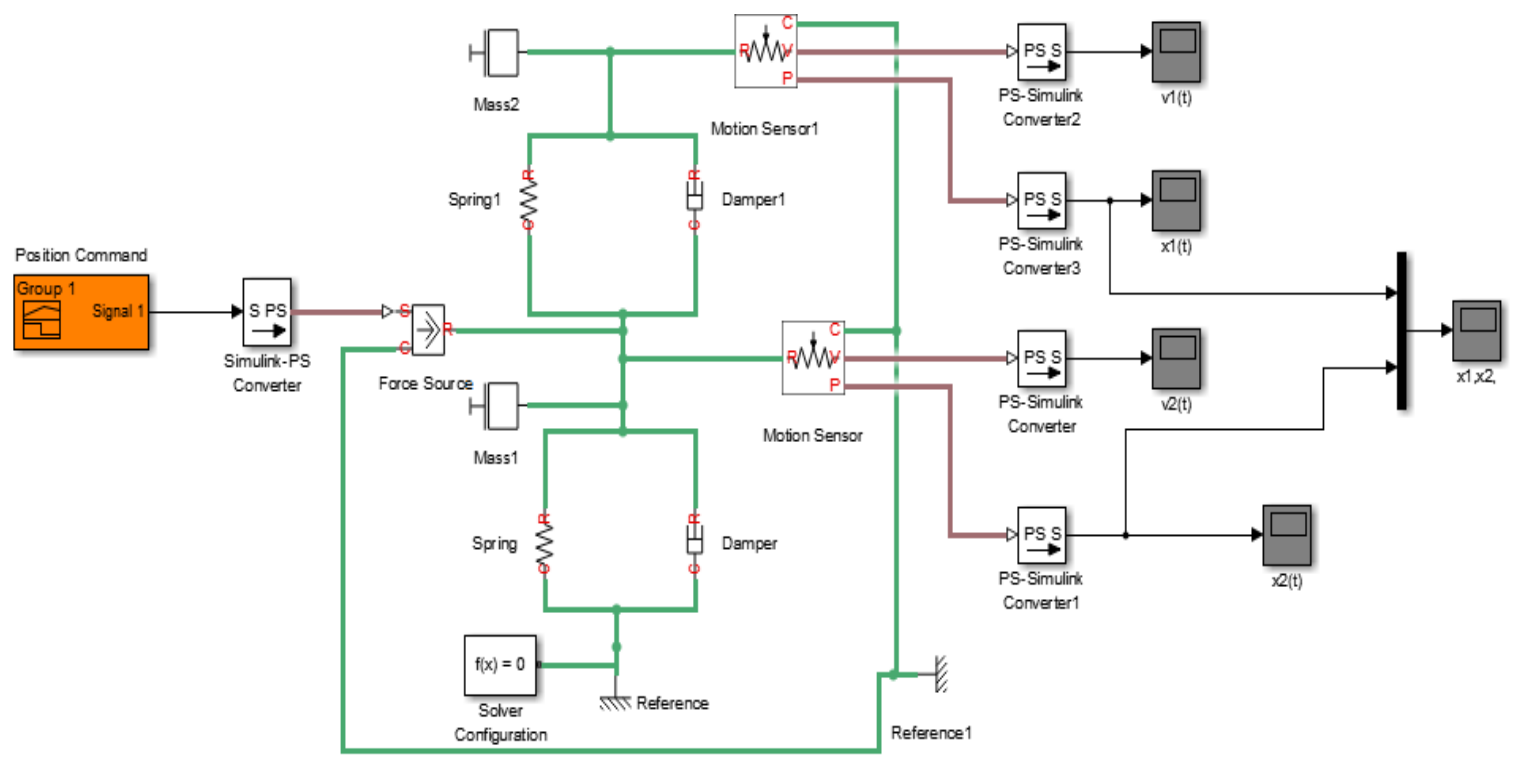

Figure 2. Simelectronics model for a coupled mass spring damper system

Furthermore, it provides the detailed function of each block that represents the mathematical model of the dynamic system and such model is often reduced to first order differential equation to simulate the dynamic accurately. It is dominant among other software in the engineering field because it enables rapid design, simulation, verification, testing and debugging of virtual prototypes of a model prior to real-time implementation. As a result of flexibility and efficient in use, it permits conversion of MATLAB code to other source codes such as $\mathrm{C}, \mathrm{C}^{++}$for real-time implementation especially in embedded systems and robotic.

Simulink and Simelectronics based Position Control of a Coupled Mass-Spring Damper ... (Okubanjo A.A) 
Simulink model of a coupled mass spring damper system is prepared with the mathematical model presented through Equations (21) and (22). PD controller is implemented to track the masses position and Figure 3 represents a schematic of the Simulink model.

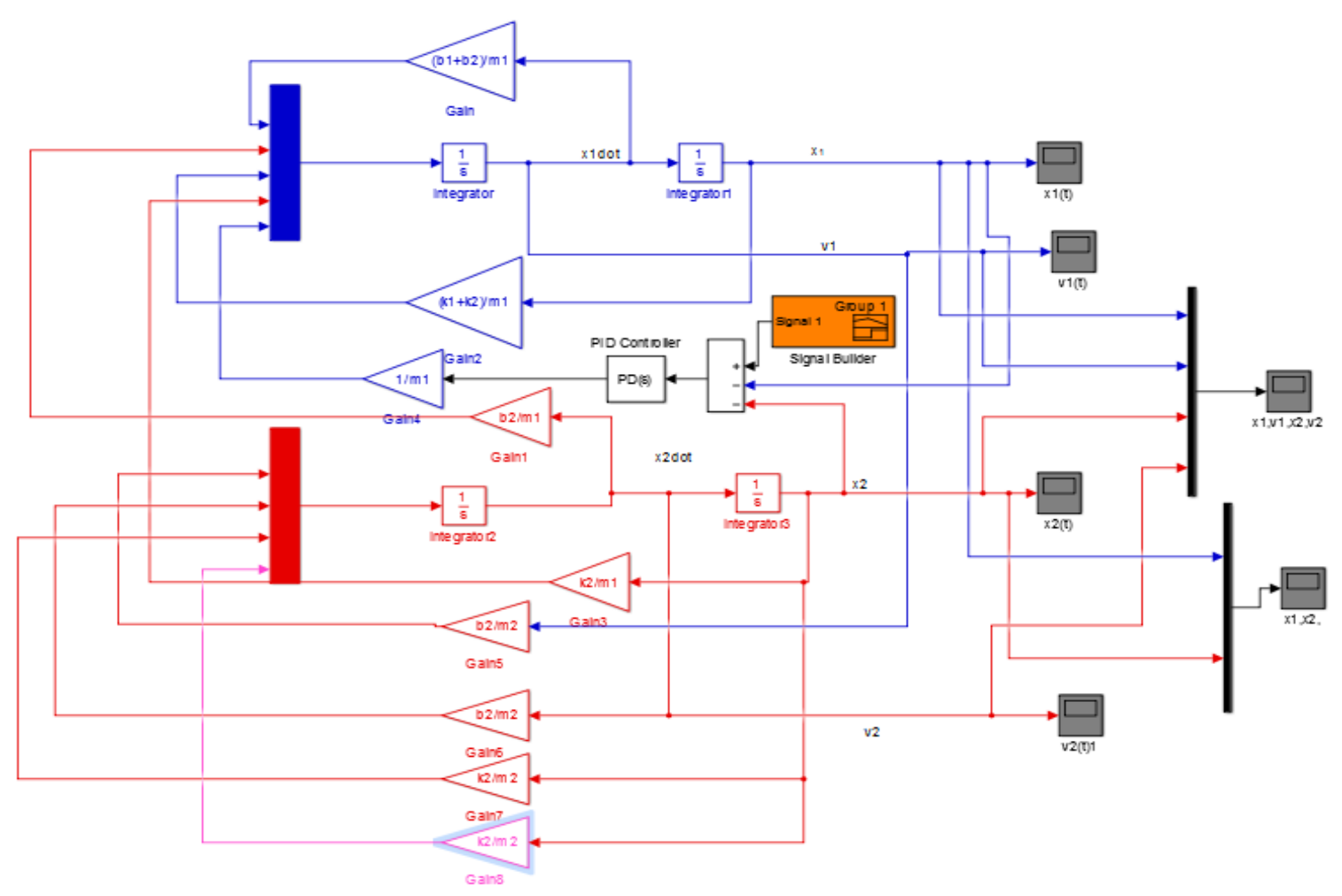

Figure 3. Simulink model for a coupled mass spring damper system

\section{PD CONTROLLER IMPLEMENTATION}

The control goal is to stabilize the position of the masses by minimizing the error and to achieve this stated objective a proportional-Derivative controller is implemented in such a way that the gain of the proportional controller, $\mathbf{k}$, is high to produce a fast system and the derivative gain $\mathbf{k}_{\mathbf{d}}$, is select in a manner to decrease the oscillation. The PD controller algorithm combines the P-action and D-action to adjust the system. It is a two-term controller that is coined from the PID controller by setting the integral action to zero. The term domain expression for PD controller is given as:

$$
u_{c}(t)=k_{p} e(t)+k_{D}(t) \frac{d e(t)}{d t}
$$

In the Simulink and Simelectronics models, a PD controller is implemented from the PD block in the Simulink toolbox library and converted to a physical system with Simulink-PS converter for the Simelectronics. The tuning of control parameters is done using PID tuner and the best performance of the controller parameter values are selected.

\section{RESULTS AND ANALYSIS}

This paper proposed a novel approach of simulating the system dynamics of a couple mass spring damper system and compared the performance with the Simulink approach.

The Simulink model was established based on the derived mathematical model and the force that mimic an obstacle commonly experienced are build with a signal builder block. Parameters used in the model were $\mathrm{m}_{1}=250 \mathrm{~kg}, \mathrm{~m}_{2}=300 \mathrm{~kg}, \mathrm{k}_{1}=80,000 \mathrm{~N} / \mathrm{m}, \mathrm{k}_{2}=5000 \mathrm{~N} / \mathrm{m}, \mathrm{b}_{1}=200 \mathrm{~N}-\mathrm{s} / \mathrm{m}, \mathrm{b}_{2}=15,000 \mathrm{~N}-\mathrm{s} / \mathrm{m}$ and to validate the mathematical model a Simelectronics and Simulink models were compared and the simulation was then tested with and without a controller. The response of the mass positions are illustrated in Figure 4 
and Figure 5 .The curve reveals that, without the implementation of the controller the positions of the masses overshoot sharply and then sustained an oscillation for about 7.6 secs before settling to zero at 10 sec.

Figure 6 shows the performance of both models in the absence of control strategy, hence, the curve shows that the system has complex conjugate poles near the imaginary axis and this dominates the transient response of the mass-spring-damper system which eventually resulted in oscillation and this led to system instability.

However, it is challenging to stabilize or control the model with the proportional controller alone irrespective of the value of gain $\mathrm{K}$ chosen, hence, a combination of proportional and the derivative controller is implemented to compensate for fast response and steady error respectively. Figure 7 and Figure 8 show the responses of the displacements of the masses with the implementation of PD controller. According to the Figure 7, Figure 8, the PD-action damped the oscillation and stabilized the positions by compensating for the steady error. In Figure 9, both models were compared under the influence of PD controller and the controller compensates for the error in the position and stabilized the positions to zero within a settling time of $6.5 \mathrm{sec}$ and significantly reduced the overshoot by $99.5 \%$ and $99.7 \%$ in Simulink and Simelectronics respectively. It can also be noted from the graph that, the responses of both model show a similar result. Furthermore, the results revealed that, modeling of the mathematical equation in Simulink and assembling of the physical system in Simelectronics give a similar result. In much related research work [27], the dynamics are transformed into transfer function model using Laplace transformation to aids system analyze in the frequency domain as well as allows motion controller implementation. Thus, this is quite complicated and tedious for a complex system with several degree-of-freedom. However, the novel Simelectronics approach provides a quick and fast approach to model, integrate complex systems and control multi-domain systems by eliminating rigorous mathematical formulation of the system's dynamics. It is also suitable for fresh engineering students' who need to perform laboratory works on systems control and related engineering courses that require modelling and simulation.

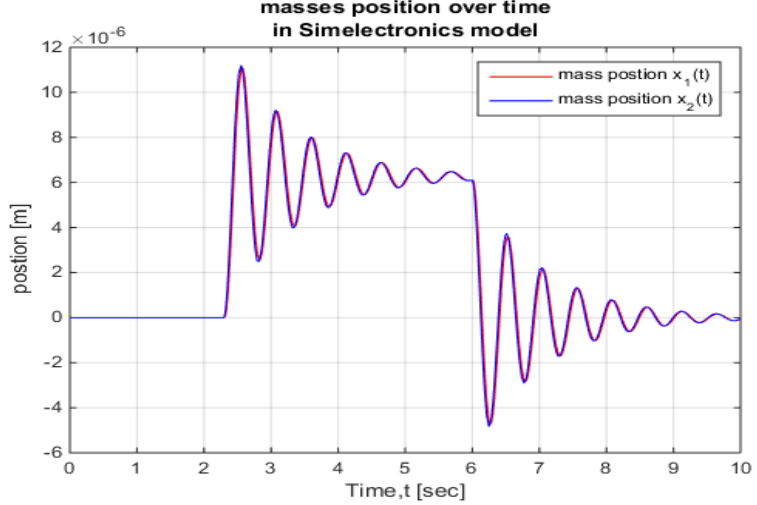

Figure 4. Displecements without controller in simelectronics model

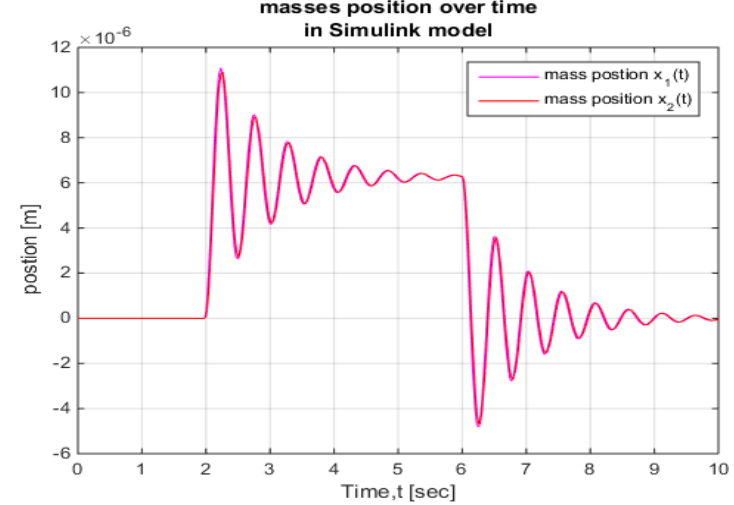

Figure 5. Postions without controller in simulink model

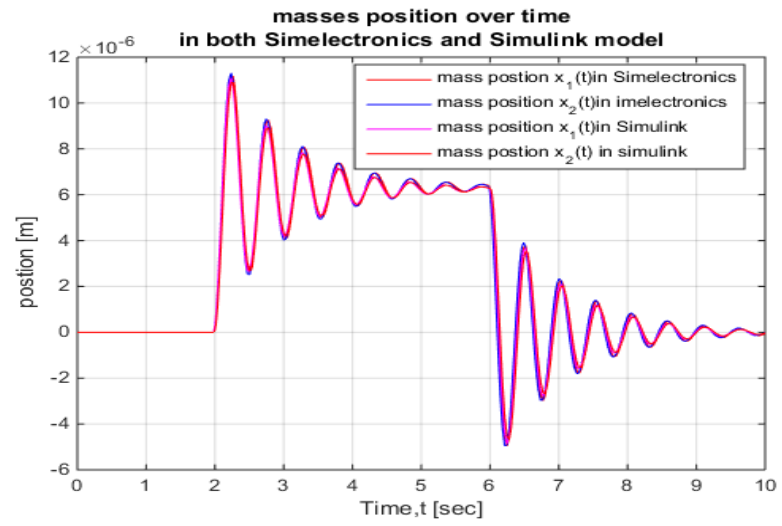

Figure 6. Postions in both simelectronics and simulink models without controller 


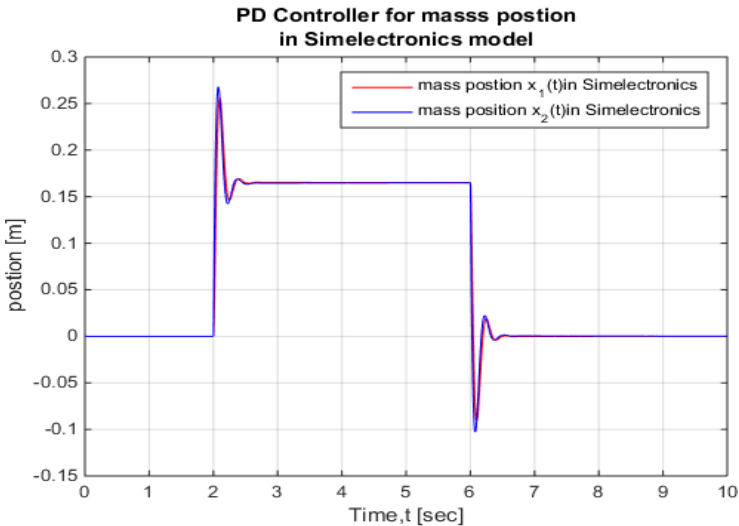

Figure 7. Positions response with PD controller in Simelectronics model

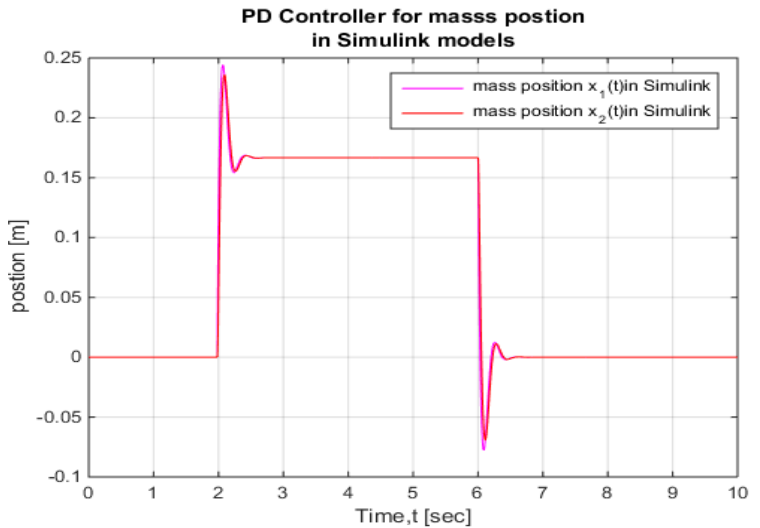

Figure 8. Positions response with PD controller in Simulink model

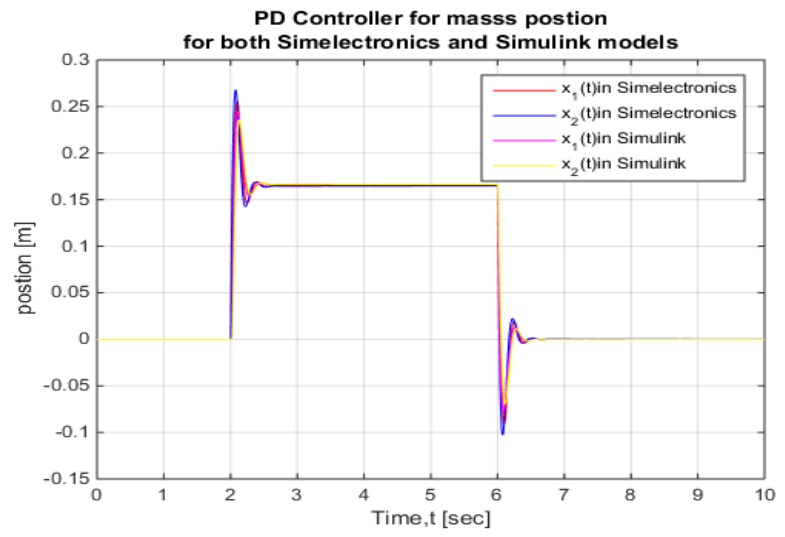

Figure 9. Position responses of both Simelectronics and Simulink model

\section{CONCLUSION}

In this paper, Simulink and Simelectronics model for position control of a coupled mass-springdamper system were developed and presented. The mathematical model was formulated based on energy property of Lagrange approach and Rayleigh's dissipation function to account for dissipative force in the model, hence, the control strategy and Simulink simulation were expanded on the derived mathematical model while the physical system was set up in the Simelectronics to stimulate the dynamic. A proportionalDerivative (PD) controller was implemented for both the models. It can be concluded from the study that both models produced the same results, but the response time of the positions was slightly shorter in Simulink than that of the Simelectronics. It can also be deduced that it was simple, easy, less time-intense and requires no mathematical model to model in the Simelectronics than Simulink, although, Simulink provided the advantage of a sdetailed representation of the mathematical model. In our future work, we would like to (1) take into account the impact of nonlinearity of the spring and damper in our model; (2) to implement state feedback controller and LQR and compare the performance; (3) analyze the effect of the spring stiffness and damping coefficient parameters by varying these parameters.

The contribution of this work is significantly expedient in the field of mechatronics and Control systems and also provides a novel approach to simulation of the mechanical system in a concise and precise method.

\section{ACKNOWLEDGEMENTS}

The authours are indebted to HAN University of Applied Sciences and Olabisi Onabanjo University for providing facilities and support. 


\section{REFERENCES}

[1] S.-M. S. Analysis, H. Ahmad, M. Tarik, H. A. Bhutta, and M. Tariq, "An Interactive Educational Tool for Double Control An Interactive Educational Tool for Double Spring- Mass-Damper System Analysis \& Control", in Proceedings of the 3rd International Conference on Engineering \& Emerging Technologies (ICEET), Superior University, Lahore, 2016, no. December.

[2] S. S. Ge, L. Huang, and T. H. Lee, "Position Control of Chained Multiple Mass-Spring-Damper Systems Adaptive Output Feedback Control Approaches", Int. J. Control. Autom. Syst. Vol., vol. 2, no. 2, pp. 144-155, 2004.

[3] K. V. Allamraju, "Dynamic Analysis of an Automobile Suspension System", IPASJ Int. J. Mech. Eng., vol. 4, no. 7, pp. 15-21, 2016.

[4] N. Katal and S. K. Singh, "Optimization of PID Controller for Quarter-Car Suspension System using Genetic Algorithm”, Int. J. Adv. Res. Comput. Eng. Technol., vol. 1, no. 7, pp. 30-32, 2012.

[5] A. El-Nasser, S. Ahmed, A. S. Ali, N. M. Ghazaly, and G. T. Abd El-Jaber, "Pid Controller of Active Suspension System for a Quarter Car Model”, Int. J. Adv. Eng. Technol., vol. 8, no. 6, pp. 899-909, 2015.

[6] M. Akpakpavi, "Modeling and Control of a Car Suspension System Using P , PI , PID , GA-PID and Auto- Tuned PID Controller in Matlab/Simulink", J. Multidiscip. Eng. Sci. Stud., vol. 3, no. 3, pp. 1506-1513, 2017.

[7] G. Srinivasan, M. S. Kumar, and A. M. J. Basha, "Mathematical Modeling and PID Controller Design Using Transfer Function and Root Locus Method for Active Suspension System", Middle-East J. Sci. Res., vol. 24, no. 3, pp. 622-627, 2016.

[8] N. Bahiah, M. Noor, and M. R. Ahmad, "Modeling the Vibrational Dynamics of Piezoelectric Actuator by System Identification Technique", vol. 7, no. 3, pp. 1506-1512, 2017.

[9] S. Kundu and H. B. Nemade, "Modeling and Simulation of a Piezoelectric Vibration Energy Harvester", Procedia Eng., vol. 144, pp. 568-575, 2016.

[10] R. Caliò et al., "Piezoelectric Energy Harvesting Solutions", Sensors, vol. 14, no. 12, pp. 4755-4790, Mar. 2014.

[11] S. F. Sulaiman et al., "Enhanced Position Control for Pneumatic System by Applying Constraints in MPC Algorithm”, Int. J. Electr. Comput. Eng., vol. 7, no. 3, p. 1633, Jun. 2017.

[12] R. Mei and M. Chen, "Robust Position Control of Electro-mechanical Systems", TELKOMNIKA (Telecommunication, Computing, Electronics and Control), vol. 11, no. 3, pp. 1674-1681, 2013.

[13] P. Sivák and D. Hroncová, "State-Space Model of a Mechanical System in MATLAB/Simulink", Procedia Eng., vol. 48, pp. 629-635, 2012.

[14] A. Tandel, A. R. Deshpande, S. P. Deshmukh, and K. R. Jagtap, "Modeling, Analysis and PID Controller Implementation on Double Wishbone Suspension Using SimMechanics and Simulink", Procedia Eng., vol. 97, pp. 1274-1281, 2014.

[15] M. Moravič, O. Ostertag, and D. Hroncová, "Simulation of Three-mass Mechanical System using MATLAB Software", J. Autom. Control, vol. 3, no. 3, pp. 114-117, 2015.

[16] E. K. Orhorhoro, D. S. Polytechnic, M. E. Onogbotsere, D. S. Polytechnic, A. E. Ikpe, and U. Kingdom, "Simulation of a mass spring damper model in phase variable", ELK Asia Pacific J. Mech. Eng. Res., vol. 2, no. 2, 2016.

[17] J. O. Kiran and D. Shivalingappa, "Study on the Effect of Position of the Dampers in Systems with 3 Degrees of Freedom", Int. J. Eng. Technol. Adv. Eng., vol. 3, no. 4, pp. 155-163, 2013.

[18] R. Sharma, D. K. Pathak, and V. K. Dwivedi, "Modeling \& Simulation of Spring Mass Damper System in Simulink Environment", in XVIII Annual International Conference of the Society of Operations Management Theme: Operations Management in Digital Economy, 2014, no. May 2016, pp. 205-210.

[19] P. Frankovský, D. Hroncová, I. Delyová, and I. Virgala, "Modeling of Dynamic Systems in Simulation Environment MATLAB/Simulink - SimMechanics", Am. J. Mech. Eng., vol. 1, no. 7, pp. 282-288, 2013.

[20] S. N. J.Rahman, M.Mushtaq, A.Ali, Y.N.Anjam, "Journal of Faculty of Engineering \& Technology", J. Fac. Eng. Technol. J. homepage, vol. 18, no. 92, pp. 47-57, 2011.

[21] S. Rannen, C. Ghorbel, and N. B. Braiek, "Nonlinear Identification and Control of Coupled Mass-Spring-Damper System using Polynomial Structures", Int. J. Adv. Comput. Sci. Appl., vol. 8, no. 5, 2017.

[22] A. Malas and S. Chatterjee, "Amplitude Controlled Adaptive Feedback Resonance in a Single Degree-of-Freedom Mass-Spring Mechanical System”, Procedia Eng., vol. 144, pp. 697-704, 2016.

[23] A. A. Okubanjo and O. K. Oyetola, Amity J. Eng. Technol., vol. 2, no. 1, pp. 1-18, 2017.

[24] C. Urrea and J. Pascal, "Parameter Identification Methods for Real Redundant Manipulators", J. Appl. Res. Technol., vol. 15, pp. 320-331, 2017.

[25] N. Norman S, Control Systems Engineering, Sixth. River Street Hoboken: Sons, John Wiley \& Sons, 2011.

[26] J. M. Kane, “A user' guide to Simscape”, Acta Psychiatr. Scand., vol. 123, no. 6, pp. 407-408, Jun. 2011.

[27] S. G. Zhang and X. P. Dang, "Modeling of Mass-Spring-Damper System by Complex Stiffness Method", Adv. Mater. Res., vol. 983, no. October 2014, pp. 420-423, 2014. 


\section{BIOGRAPHIES OF AUTHORS}

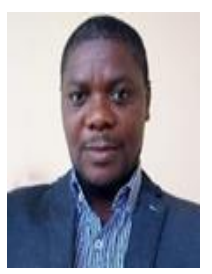

A. A. Okubanjo received B.Sc Degree in Electrical \& Electronics Engineering with First Class Honour from Olabisi Onabanjo University, Nigeria in 2009 and completed M.Sc in Control Systems Engineering from HAN University of Applied Sciences, the Netherlands in 2016. He is a lecturer in the Department of Computer and Electrical \& Electronics Engineering at Olabisi Onabanjo University. He is a shrewd academician with interest in Control System and Instrumentation, Renewable Energy, Mechatronics, Safety and Systems, Information technology and Image processing. He has attended workshops, seminars and conferences related to control systems Engineering and he has also published and submitted papers for review on the listed areas of interests

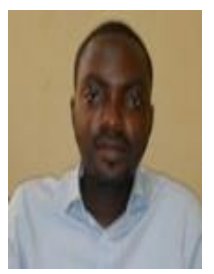

O. K. Oyetola is a faculty member at the department of Computer and Electrical Engineering, Olabisi Onabanjo University, Nigeria. He received B.Sc. Degree in Electrical and Electronic Engineering from the same University in 2009. In 2016, he completed M.Tech in Electrical and Electronic Engineering at Ladoke Akintola University, Ogbomoso, Nigeria. He is a shrewd academician with interest in Smart grid, Energy management, Software Engineering, Cloud computing, IoT, Big data and Digital communication.

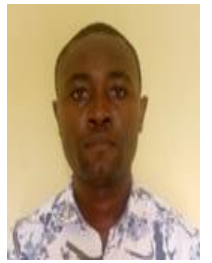

O. O. Olaluwoye obtained his B.Sc. Degree in Electrical/Electronics Engineering from Olabisi Onabanjo University, Nigeria in 2008. He completed his M.Tech program in Electrical and Electronic Engineering from Ladoke Akintola University of Technology, Ogbomoso, Nigeria in 2016. He is a registered Engineer with the Council of Regulation of Engineering in Nigeria (COREN). His research interests are in Power Systems Engineering, Renewable Systems, Software Development Systems, Smart Grids and Systems Reliability. He has worked in the Nigerian Electricity sector. He is currently a lecturer at Olabisi Onabanjo University, Nigeria. 